\title{
PERSPECTIVE
}

\section{Trials of inhaled Iloprost and other new vasodilating prostaglandins}

\author{
T. Higenbottam*, T. Siddons*
}

Pulmonary hypertension in its many different forms [1] was considered untreatable until the 1990s. With the exception of pulmonary hypertension associated with hypoxic lung disease, where long-term oxygen therapy (LTOT) improves survival in those patients with respiratory failure [2], the various forms of the disease often progress rapidly and lead to premature death. Work carried out in the early 1980s suggested that long-term, continuous intravenous prostacyclin might increase survival in severe primary pulmonary hypertension (PPH) [3, 4]. However, these papers reported unrandomized studies. This was also true of a report that showed that long-term anticoagulation improved survival in PPH and chronic thrombo-embolic pulmonary hypertension [5]. Although these findings were encouraging, it remained unusual for PPH patients to receive these therapies.

A randomized, controlled trial was undertaken in the USA, comparing long-term prostacyclin therapy plus conventional therapy, with conventional therapy alone, and was a landmark in the study of PPH. It not only applied strict entry criteria for PPH patients in the New York Heart Association (NYHA) grade III and IV, but was sufficiently "powered" to test whether the treated group might demonstrate improved exercise tolerance as measured by the six-minute walk test. Quality of life was measured using the Nottingham Health profile questionnaire. Indeed, the prostacyclin treated patients demonstrated better exercise tolerance and enhanced quality of life after 3 months [6]. Surprisingly, and perhaps fortuitously, survival was also improved in the treated group at 3 months.

This study has defined how future studies should be undertaken in pulmonary hypertension. It also led to the Food and Drug Administration issuing a license for prostacyclin in the treatment of PPH in the USA. Approval was also subsequently granted in France, Canada, Austria, Italy, and Holland. Indeed, for patients with isolated pulmonary arterial hypertension and scleroderma, a further randomized, controlled study of prostacyclin demonstrated improved quality of life [7]. As a result, prostacyclin can be considered an effective treatment, superior to lung transplantation in enhanc-

Medicine and Pharmacology, Division of Clinical Sciences, The Medical School, University of Sheffield, Sheffield, UK.

Correspondence: T. Higenbottam, Medicine and Pharmacology, Division of Clinical Sciences, The Medical School, University of Sheffield, Sheffield S10 2RX, UK, Fax: 441142711711. ing quality of life and improving survival. In addition to intravenous prostacyclin, its analogues, such as oral Beraprost (Toray Industries Inc., Japan) [8] and inhaled Iloprost (Schering AG, Germany) [9] have also been demonstrated to be effective in uncontrolled studies. Encouraged by these, large-scale, randomized, controlled studies are presently being undertaken and are to be applauded. A similar large-scale, randomized, controlled study has recently been completed for another subcutaneously delivered prostacyclin analogue, Uniprost (United Therapeutics Corporation, USA).

The negative findings in the report in this journal regarding iloprost, "Lack of long-term haemodynamic improvement with chronic inhaled Iloprost in precapillary pulmonary hypertension" might dampen enthusiasm for the inhaled route. However, it follows another series report in the New England Journal of Medicine, which demonstrates sustained falls in pulmonary vascular resistance with long-term use of inhaled Iloprost [10]. The randomized, controlled trial should be awaited before passing judgement, but it does not lessen the value of reporting uncontrolled effects of drugs.

Without such series reports, an early view of therapies for this devastating condition of pulmonary hypertension cannot be obtained. However, the final decision of clinical use should await the positive findings in a randomized, controlled trial. This must be the right approach given the high cost of the prostaglandin therapies, which can exceed 70,000 Euros per year.

\section{References}

1. Rich S, ed. Executive Summary from the World Symposium on Primary Pulmonary Hypertension. The World Health Organization, 1998.

2. Long term domiciliary oxygen therapy in chronic hypoxic cor pulmonale complicating chronic bronchitis and emphysema. Report of the Medical Research Council Working Party. Lancet 1981; 1(8222): 681-686.

3. Higenbottam TW, Wheeldon D, Wells F, Wallwork J. Long term treatment of primary pulmonary hypertension with continuous intravenous Epoprostenol (prostacyclin). Lancet 1984; 1(8385): 1046-1047.

4. Jones DK, Higenbottam TW, Wallwork J. Treatment of primary pulmonary hypertension with intravenous Epoprostenol (prostacyclin). B Heart J 1987; 57: 270278.

5. Fuster V, Steele PM, Edwards WD, Gersh BJ, McGoon MD, Frye RL. Primary pulmonary hypertension: 
natural history and the importance of thrombosis. Circulation 1984; 70: 580-587.

6. Barst RJ, Rubin LJ, Long WA, et al. A comparison of continuous intravenous Epoprostenol (prostacyclin) with conventional therapy for primary pulmonary hypertension. The Primary Pulmonary Hypertension Study. N Engl J Med 1996; 334: 296-302.

7. Badesch DB, Tapson VF, McGoon MD, et al. Continuous intravenous epoprostenol for pulmonary hypertension due to the scleroderma spectrum of disease. A randomized, controlled trial. Ann Intern Med 2000; 132: 425-434.
8. Nagaya N, Uematsu M, Okano Y, et al. Effect of orally active prostacyclin analogue on survival of outpatients with primary pulmonary hypertension. J Am Coll Cardiol 1999; 34: 1188-1192.

9. Olschewski H, Ghofrani HA, Schmehl T, et al. Inhaled iloprost to treat severe pulmonary hypertension. An uncontrolled trial. German PPH Study Group. Ann Intern Med 2000; 132: 435-443.

10. Hoeper MM, Schwarze M, Ehlerding S, et al. Longterm treatment of primary pulmonary hypertension with aerosolized iloprost, a prostacyclin analogue. $N$ Engl J Med 2000; 342: 1866-1870. 